\title{
LAS RELACIONES INTERSUBJETIVAS Y SU VINCULACIÓN CON EL RIESGO EDUCATIVO: RASGOS DE ESTILO Y CULTURA DE LA ESCUELA ESTUDIADA
}

\author{
Pablo Bulfon (Universidad Nacional del Comahue)* \\ pablo_bulfon@yahoo.com.ar
}

Recibido: 30/07/2012 Aceptado: 27/11/2012

\section{Resumen}

Algunos elementos de la cultura institucional de las escuelas pueden favorecer la producción de relaciones intersubjetivas entre docentes y alumnos. Estos elementos, sostenidos por el equipo directivo, enlazan a todos los integrantes de la institución, les provee de sentidos a la tarea que realizan, actúan inyectando significados acerca de lo que hay que hacer y cómo hay que hacerlo. Los estudios que realizamos en una escuela secundaria, un CPEM de la ciudad de Neuquén, nos permiten explorar la relación que se establece entre cultura institucional e intersubjetividad. Las entrevistas realizadas al equipo directivo de la escuela expresan esa relación, dando cuenta del compromiso y responsabilidad de los docentes cuando se alinean a un proyecto cuya finalidad es contener a todos los alumnos de la comunidad escolar.

Abordaremos la relación entre cultura institucional e intersubjetividad a partir de las operaciones de diverso tipo que los docentes efectúan alrededor del Proyecto Educativo Institucional (PEI). Hacia el final del artículo, proponemos revisar los conceptos tratados a fin de incluirlos en futuros debates en relación a la temática de nuestra investigación.

\section{Palabras claves}

Riesgo Educativo - Escuela Secundaria - Proyecto Institucional - Intersubjetividad - Cultura Institucional.

* Diploma Superior en Ciencias Sociales con mención en Gestión de las Instituciones Educativas - FLACSO. Profesor en Ciencias de la Educación. Facultad de Ciencias de la Educación - Universidad Nacional del Comahue. Profesor en Educación Musical. Escuela Municipal de Música de la ciudad de Neuquén. 


\section{Abstract}

Some elements of the institutional culture of schools can promote the production of inter-relationships between teachers and students. These elements, supported by management, link to all members of the institution, providing them with directions to the work they do, act injecting meanings about what to do and how to do it.

Studies conducted in a school, a CPEM city of Neuquén, allow us to explore the relationship established between organizational culture and intersubjectivity. Interviews with the school management team express this relationship, realizing the commitment and responsibility of teachers when aligned to a project which aims to hold all the students of the school community.

We will address the relationship between organizational culture and intersubjectivity from operations of various kinds that teachers made about Institutional Educational Project (PEI). Towards the end of the article, we propose to review the concepts discussed for inclusion in future discussions on the theme of our research.

\section{Key words}

Risk Education - School - Institutional Project - Intersubjectivity - Institutional Culture.

\section{Introducción}

La ciudad de Neuquén es, por numerosa, la urbe más importante del Alto Valle de Río Negro y Neuquén. En ella conviven más de 360.000 personas, en distintas condiciones económicas, sociales y culturales (1). El paso del tiempo encuentra que las ciudades vecinas están componiendo una demografía que reconoce ciertas semejanzas entre sus localidades. De a poco y sin pausa, como el río que los divide; el Alto Valle va transformando su paisaje hasta hacerse una sola en ambas orillas.

Las escuelas de las provincias transitan estas mismas regularidades. Ellas destinan una gran parte de sus esfuerzos a sostener una tarea que en las condiciones actuales se presenta como difícil, compleja, entreverada. Aunque siempre lo fue (la educación es una complejidad), cabe decir que ahora es más que antes. Perplejas (Lewkowicz, 2006), atónitas, sin la fortaleza que le daban las respuestas tradicionales a los problemas cotidianos; ellas buscan nuevas maneras de realizar la tarea institucional: asegurar los aprendizajes a sus alumnos, socializarlos, contener y crear una pertenencia que provea, a todos, de elementos para la construcción de identidades.

Así y todo, su finalidad y medios es puesta, más de las veces, en duda.

Sobre este fondo de situación (que seguramente no es diferente en otras provincias argentinas), observamos que las escuelas de Río Negro y Neuquén son en la actualidad objeto de políticas educativas nacionales y provinciales que intentan producir transformaciones en su geografía conocida. La necesidad de revisión de la Ley Orgánica de Educación, a través de la Ley 4737/11 de la 
legislatura de Río Negro, declara abierto un proceso de debate cuya finalidad es la promulgación de una nueva ley provincial "... adecuada a las necesidades actuales..." (Art. 150; Ley 4737/11/RN) En igual sentido, en diciembre de 2011 ingresa para su tratamiento por la legislatura provincial de Neuquén, un anteproyecto de Ley Orgánica de Educación, en el marco del cumplimiento de la Ley 2724/10, que en artículo $2^{\circ}$ solicita al Foro Educativo Provincial la sanción de una norma con la finalidad de "... mejorar la calidad y garantizar la inclusión educativa." Fruto de una lógica que se agota poco a poco, las leyes pretendidas responden a la constatación de una situación que se establece casi con pavorosa normalidad: las escuelas no son como venían siendo. Las escuelas ya no responden "... a la cultura adolescente y las nuevas tecnologías". (2). "Vemos que las argumentaciones sobre el declive de lo escolar en tiempos de estallido del yo (Bleichmar, 2009) son extensas y circulan por todos los ámbitos de discusión. A colación, extraemos un argumentación que tiene fuerte adhesión entre los docentes de las escuelas estudiadas: “... las formas escolares habituales y las autoridades que le daban sentido ya no producen los efectos esperados." (Greco, 2007, p. 19)

El propósito de este artículo es explorar algunos elementos de la cultura institucional de la escuela estudiada que sostienen la producción de relaciones intersubjetivas. Creemos que entre estos elementos se juega un modo de respuesta al contexto brevemente descripto, denominado en esta ocasión como contexto adverso. Presentaremos una primera parte de los resultados del proyecto de investigación "Las relaciones intersubjetivas en instituciones del nivel medio y su vinculación con la construcción del riesgo educativo" (FACE - UNCo), cuya principal finalidad es contribuir a la comprensión del complejo entramado que participa en generar los altos índices de repitencia, sobreedad y bajo rendimiento que se registra en nuestro país y particularmente en la escuela media estatal de la Provincia de Neuquén. La preocupación por estudiar e indagar este objeto de estudio surge de los interrogantes formulados en una investigación anterior, denominada "Cómo se construye el riesgo educativo. Un estudio desde el decir y el hacer de los protagonistas institucionales" (FACE - UNCo). En la actualidad, y siguiendo los interrogantes iniciales vinculados a la construcción social del riesgo educativo, prestamos especial atención a la producción del vínculo intersubjetivo entre docentes y alumnos, como condición necesaria para la realización de los aprendizajes.

Desplegaremos en primer lugar los marcos teóricos y metodológicos que trazan un campo de referencia para la investigación. Ellos son parte del esfuerzo de reflexión continua para elucidar los sostenes epistemológicos que se hallan en la base del proceso de investigación iniciado. En este sentido, adelantamos que lejos de todo dogmatismo teórico - metodológico, pensamos que la metodología se crea y recrea a lo largo de todo el proceso de investigación, siendo el diseño inicial una propuesta que necesariamente se reformula. Respecto 
al marco conceptual trazaremos brevemente la vinculación entre intersubjetividad, riesgo educativo y estilo y cultura institucional. En este punto, nuestra investigación considera que las culturas escolares sostienen condiciones que favorecen u obstaculizan los aprendizajes. En segundo lugar, presentaremos sintéticamente - a partir del análisis de las entrevistas realizadas al equipo directivo (3) de la escuela estudiada, un Centro Provincial de Educación Media de la Ciudad de Neuquén- los rasgos centrales que conforman un estilo de funcionamiento, que dan cuenta de una cultura institucional ocupada en dar respuesta a las condiciones que les formula el contexto adverso.

Entendemos que los protagonistas de la comunidad educativa de la escuela estudiada tienen en "común" (4) un proyecto institucional que direcciona la tarea, que está internalizado en los sujetos y cuyo propósito principal es crear las condiciones para que los alumnos se constituyan como sujetos en y de la cultura. Por último, concluiremos retomando las ideas formuladas a lo largo del escrito y realizaremos nuevos aportes acerca del objeto de estudio, a partir de los desarrollos obtenidos hasta el momento.

\section{Encuadre teórico de la investigación}

La problemática estudiada se enmarca en la Psicología Educacional, que supone el entramado de diversas teorías explicativas. Una primera delimitación conceptual en la construcción de nuestro objeto teórico nos lleva a dar cuenta de la lógica inherente de la institución escolar en el marco de contextos históricos - sociales actuales. En este sentido, las instituciones educativas se constituyen en espacios privilegiados de entrelazamiento vincular donde los procesos que se desatan en el interior de su dinámica provienen de una doble referencia: la individuación y la socialización. Los establecimientos educacionales, en general, se presentan como objetos de relaciones; entre sujetos y con el establecimiento. De tal forma es la vinculación (el enlace que se genera entre la institución y los sujetos) que estos toman o asumen aspectos que son propios y característicos de la institución, ya de modo singular. A la vez, los sujetos le dan a los establecimientos institucionales parte de sí mismo, alienándose a la institución y sus mandatos, pero de un modo en que participa recreando lo que ahí sucede. En otras palabras, los sujetos son parte interviniente y constituyente de las instituciones (Kaës, 1989). Aún cuando las instituciones preceden a los sujetos, y nos inscriben en la trama de las relaciones y representaciones sociales, ellas son la externidad de un espacio interno, una parte de nosotros mismos que se encuentra fuera de sí (5).

Por esto mismo, las instituciones se presentan como formaciones sociales complejas (Garay, 1996) cuya identidad se conforma como el resultado de procesos, de interrelaciones, oposiciones y transformaciones de fuerzas individuales y sociales. Se constituyen en "espacios de intersección" de múltiples lógicas que se vinculan y entrecruzan bajo una apariencia de unidad, bajo la 
ilusión de la homogeneidad (esencial para el funcionamiento institucional) pero albergando en su interior una profunda heterogeneidad, siempre contradictoria. Se constituyen en "Espacios intersticiales" (Frigerio et al, 1992) lugar de entrecruzamiento entre lo social y lo individual, lugar con tramas abiertas que permiten o silencian las voces de los actores particulares.

Este trabajo de interlocución entre las instituciones y los sujetos, redunda en la creación de representaciones comunes; un conjunto de imágenes del establecimiento institucional en sí, de sus miembros, de la tarea y el proyecto que los une. Son creaciones que se configuran en la historia vincular de los sujetos en la institución, que condicionan la percepción que tienen de la realidad vivida. Pero además, las representaciones cumplen con la función de proporcionar identificaciones, son mojones de referencia (Fernández, 2001) cuya finalidad es hacer previsible el estatuto de las relaciones entre los sujeto y la institución, en singular. En este lugar ubicamos al Proyecto Educativo Institucional de la escuela estudiada, considerado como una herramienta básica de la actividad institucional, que reconstruye la identidad de la institución, formula los propósitos que se proponen y la estructura organizativa necesaria, a la vez que pone en marcha las acciones para lograr los objetivos y revisar los resultados. EI PEI es un organizador (6), o mejor dicho la expresión del proyecto y la tarea, del que es posible extractar ese conjunto de representaciones que dan cuenta del modo en que la escuela entiende qué es lo que hay que hacer en las actuales condiciones sociales, económicas y culturales. Sin lugar a dudas, el PEI expresa el deseo utópico del grupo por sostener y promover los aprendizajes y la inclusión, de sus alumnos, a la cultura. Es por ello que encontramos en esta herramienta una fuente valiosa de información sobre el modo que los docentes se vinculan con los alumnos y construyen intersubjetividad pedagógica. Interpretamos que una cultura institucional que favorece los aprendizajes tiene como sustrato esta realización, que consiste en producir relaciones intersubjetivas de carácter pedagógico.

\section{Intersubjetividad pedagógica}

La escuela tiene la responsabilidad pedagógica de construir condiciones de educabilidad (7) en función de la promoción del desarrollo del sujeto. De introducir a las nuevas generaciones en la cultura en tanto espacio de distribución y producción de saberes, tiene un papel irremplazable que jugar cuando pone a disposición de sus alumnos ciertos contenidos y herramientas intelectuales que otras instituciones no pueden distribuir o producir. En este sentido, se reconoce a la escuela y a los docentes en particular, como posibilitadores de espacios de construcción subjetiva en la creación de vínculos afectivos interpersonales en el que se ponen en juego los sentimientos, motivaciones y expectativas de alumnos y profesores. A través de diferentes mecanismos y significaciones, los alumnos van configurando expectativas que se traducen en una experiencia educativa singular. 
En nuestro estudio nos interesa indagar en la responsabilidad pedagógica de la escuela en construir condiciones de riesgo educativo. Es decir, admitimos que el fenómeno pedagógico del riesgo educativo tiene una doble ligazón que entrelaza las prácticas de enseñanza y de aprendizaje con las formaciones culturales más amplias que son parte de la escuela como institución, pero nuestra intención por otra parte no es una mera descripción del fenómeno; sino la visualización de aquellos aspectos y zonas que permitirían a los sujetos protagonistas intervenir sobre las condiciones de producción del riesgo educativo.

Estudiar el "riesgo educativo" es pensar en una categoría que forma parte de un proceso cultural y no en una propiedad del sujeto. No se considera que la situación de riesgo sea atribuida a desventajas socioculturales, ni a deficiencias intelectuales tal como se señalara en los análisis tradicionales, sino de reconocer en la realidad que no sólo fracasan los grupos sociales marginados, que también es una problemática que abarca a sectores medios y altos de la sociedad. En este sentido, el riesgo educativo se comprende como un efecto de la interacción del alumno con la escuela, y a través de ella con la sociedad y la cultura.

Dentro de esta problemática, entendemos el riesgo educativo como una construcción social y ligada a la educabilidad. Repasemos brevemente este último concepto: las condiciones que definen la educabilidad dependen siempre de la naturaleza de la situación de la que es parte el sujeto. R. Baquero (2002) lo define como las condiciones, alcances y límites potenciales de la acción educativa sobre sujetos definidos en situaciones definidas (8). Ahora bien, el concepto de intersubjetividad pedagógica permite enriquecer el concepto de educabilidad, a partir de la consideración de la interacción social y la actividad semiótica como unidades de análisis para capturar los procesos de desarrollo cultural específicamente humanos (Vigotsky, 1995). El concepto de intersubjetividad en Vigotsky abre una puerta para el análisis de las condiciones de educabilidad producidas por la escuela en función de la promoción del desarrollo del sujeto. De allí, que partimos de la convicción que el aprendizaje se produce a partir del encuentro intersubjetivo, esto es donde docentes y alumnos comparten la definición de la situación que los convoca. Wertsch (1988) considera que la intersubjetividad se da cuando los interlocutores comparten algún aspecto de sus definiciones de una situación. A partir de esta posición, la intersubjetividad se construye en el marco de la acción y de la actividad que realizan conjuntamente los sujetos.

\section{Estrategias Metodológicas empleadas en la investigación.}

El proyecto de investigación se inscribe en un enfoque cualitativo, con una orientación de tipo etnográfico. El análisis cualitativo permite contemplar la diversidad de la situación comunicativa y poder conocer e interpretar la red de interacciones que se producen y negocian en la vida institucional. La etno- 
grafía es considerada como una opción válida para el estudio emprendido, ya que permite analizar detalladamente lo que hacen, dicen y piensan personas vinculadas por lazos culturales y sociales. En nuestro caso, la escuela como contexto social y cultural complejo es la que determina las formas de interacción que en ella se producen, permitiéndonos analizar y comprender los modos de relaciones intersubjetivas dentro la institución. Coherentes con este enfoque metodológico se seleccionaron para la recolección de la información, la observación de diferentes clases disciplinares en dos períodos distintos (junio-agosto) y entrevistas semiestructurada, a docentes, directivos, asesor pedagógico y estudiantes (considerados informantes claves). Dichos instrumentos nos posibilitaron recuperar los procesos en los que están involucrados los participantes, pues creemos que es posible comprender las relaciones intersubjetivas a través de sus versiones, explicaciones, descripciones, sus acciones discursivas, y el significado que los protagonistas le otorgan. El estudio de caso es adecuado para un análisis intensivo y profundo de uno o pocos ejemplos de ciertos fenómenos. (Goetz y LeCompte, 1988), por ello se circunscribe el proyecto a indagar en profundidad en un Centro Provincial de Educación Media, de horario diurno, radio suburbano de la ciudad de Neuquén capital, con una población estudiantil heterogénea en cuanto a su nivel socio económico cultural.

\section{Rasgos de estilo y cultura sostenidos por el equipo directivo.}

Los docentes que conforman el equipo directivo están sometidos a una serie de tensiones y demandas que le vienen por el lugar que ocupan en la institución escolar. Ellos son el rostro de la escuela, su "cara visible", la cabeza de la organización, sus últimos responsables, los que garantizan el funcionamiento y la tarea de una organización que tiene, por tradición, características burocráticas y jerárquicas. Las vicisitudes del cargo les viene no sólo por el rol que asumen, altamente complejo, que no reconoce en lo formal una formación específica (no se estudia para director), sino también por un contexto comunitario definido por la adversidad. Los altos índices de repitencia, sobreedad y bajo rendimiento son moneda corriente en la escuela estudiada; pero también lo es el contexto comunitario de pobreza y exclusión, las adicciones y la inseguridad que conspira contra la armonía pretendida. Hacer posible hoy las condiciones institucionales para que el aprendizaje sea una realidad, tarea de la que se sienten responsables todos los integrantes del equipo directivo, se torna en una tarea por demás difícil. Probablemente, todos estamos de acuerdo en que la escuela tiene que enseñar y convocar el deseo de aprender de los alumnos; sobre este aspecto de la educación escolar hay pocas o ninguna duda. Lo novedoso lo constituye un contexto comunitario y cultural que no ayuda a que el encuentro intersubjetivo entre docentes y alumnos, condición indispensable para que el aprendizaje se realice. Es el signo que marca los tiempos que vivimos. 
La tarea de conducir un establecimiento educativo se configura "... en la articulación de una serie de rasgos propios de un tipo de instituciones y de su contexto: rasgos específicos de quienes desempeñan la tarea docente y de quienes ocupan esta posición, en particular." (Yentel et al, 2009). Esos rasgos propios de la tarea directiva, señales de un estilo de la institución, proveen datos de altísima riqueza acerca de la instalación, en la cultura escolar, de un proyecto y una tarea que identifica a la escuela. Son, dicho de otro modo, indicadores relevantes para el estudio de la intersubjetividad, ya que proveen información valiosa acerca de cómo los directores enfrentan y tematizan el contexto y las condiciones institucionales en que desarrollan su tarea.

Específicamente, aquí nos interesa describir ciertos aspectos que relatan los docentes del equipo directivo de la escuela estudiada, en relación a los alumnos y al proyecto educativo institucional. Aspectos que cuentan qué piensan sobre la escuela y cuál es la tarea a realizar. Observamos que los docentes entrevistados manifiestan una preocupación muy particular sobre la escuela en el contexto actual en el que se desenvuelve. Ven que la situación económica y social vivida por la comunidad cercana se ha ido deteriorando en los últimos años. A la par, quizás como consecuencia de esa percepción, ubican a los alumnos que concurren al CPEM en un lugar central del proyecto educativo institucional. La escuela sostiene proyectos que tienen por finalidad la retención de la matrícula, a través de la contención y la inclusión a lo escolar, dando cuenta de la genuina preocupación de los docentes por la situación social que ellos atraviesan. De esta manera, contexto adverso y centralidad de los alumnos en el proyecto educativo, son dos de los aspectos abordados, de mayor importancia, sobre el que se construye la tarea actual de la escuela estudiada. Desanudar ese entramado nos ayuda a comprender las vinculaciones de la intersubjetividad con la construcción social del riesgo educativo (9).

\section{Estilo y cultura institucional}

En principio, estilo y cultura institucional refieren a la escuela en su singularidad, es decir, a aquellos aspectos que la hacen única, a una manera particular de hacer "la escuela". A lo largo de su historia, cada escuela configura un modo idiosincrásico de funcionamiento, un modo peculiar que le pertenece, que opera con las condiciones de diverso tipo para conseguir un determinado resultado (Fernández, 1998). El modo de funcionamiento idiosincrásico permanece en el tiempo, se reitera, constituye una regularidad, incluye aspectos o cualidades muy disímiles: procesos de producción y sus resultados, valores sostenidos por los grupos, estrategias para enfrentar y resolver las dificultades que les presenta la vida institucional y concepciones pedagógicas. En este último aspecto puede incluirse el Proyecto Educativo Institucional. Como dijimos antes, lo tematizamos como un organizador de la tarea de la escuela. 
De las entrevistas observamos que el PEI es un proyecto no escrito, no expresado en el papel impreso, ni se encuentra archivado en los extensos biblioratos de la secretaría. Aún así, todos los docentes saben de qué se trata y en qué consiste. Como proyecto de carácter institucional, el PEI organiza la tarea escolar del año lectivo y provee de elementos que cohesionan fuertemente lo que hay que hacer. Es, básicamente, las acciones y la orientación para esas acciones.

Cuando los docentes entrevistados dicen que tienen un $\mathrm{PEI}$, refieren a un conjunto de proyectos incluidos en él, de diverso tipo y nivel. Además, incluyen un conjunto de ideas que sostiene las acciones diseñadas en los proyectos. Este ideario del grupo, expresado especialmente por el equipo directivo, significa las acciones de los docentes y le dan un carácter único, singular.

¿Por qué el PEI es un proyecto no documentado? Su escritura supone un proceso de elaboración en el que interviene el colectivo docente, específicamente, y en ciertas ocasiones también los alumnos, los padres y el personal de portería. Pero los docentes entrevistados dicen que no hay tiempo para la escritura ni para los debates alrededor del proyecto institucional, ya que el contexto social actual impone un ritmo diferente al acostumbrado, uno que deviene del trabajo con los acontecimientos (10), tal como se presentan en la tarea cotidiana. Este pragmatismo se resume en la frase del vicedirector, cuando expresa que: "... no hablemos de las cosas, hagamos las cosas".

En síntesis, el PEI se orienta a partir de algunas ideas centrales, que dan cuenta de las representaciones e imaginarios de la cultura institucional, compartida y defendida por el equipo directivo. Ellos se consideran los guardas del PEI, sus custodios y sus impulsores, los que tienen la responsabilidad de llevarlo a cabo. Son funciones que se inscriben en el espacio abierto por las regulaciones instituidas, y que movilizan las producciones simbólicas más importantes que habitan la cultura institucional. Describir esas ideas, agrupadas según los tópicos que fueron hablando los entrevistados, es lo que sigue a continuación. Aclaramos que no pretendemos realizar un examen exhaustivo de cada uno de los temas hablados por los docentes, sino simplemente referirnos a ellos en su producción más importante. Abordaremos entonces sólo los más relevantes, agrupados en dos tópicos: a) la importancia otorgada a la buena relación docentes - alumnos, ajustada a los valores de reconocimiento del otro y confianza en sus posibilidades, que se advierte en la centralidad que ocupan los alumnos en el PEl; b) el valor otorgado a la palabra, como mediación entre la acción y el pensamiento, puesto en el lugar de ejemplo, que educa y construye valores positivos. Extraeremos algunas citas para estos aspectos. En el último título, trataremos de retomar estos temas a fin de vincularlos al objeto de estudio de nuestra investigación. 


\section{La relación con los alumnos}

En el centro de las actividades organizadas por el PEl están los alumnos. Ellos son sus destinatarios exclusivos. Observamos que esta centralidad se enlaza con las representaciones culturales instituidas sobre los alumnos, con la percepción que los docentes tienen de la comunidad que atiende la escuela y con el modo en que dan respuesta a las vicisitudes del contexto. Los alumnos son ubicados en estas coordenadas, y de este modo son incluidos en el proyecto escolar.

En las entrevistas, observamos que los alumnos son representados como buenos chicos, excelentes, sin problema de disciplina. "... los chicos que vienen a la escuela son santos", expresa el vicedirector. Su mayor cualidad es que, a pesar de todo, asisten a la escuela, asignándoseles un valor positivo a tal hecho. La asesora pedagógica afirma que "... como característica positiva de los alumnos que están, es que vienen..." Que los alumnos asistan a la escuela, en las condiciones actuales en que esta se desenvuelve, es por cierto un suceso muy valorado por los docentes. Estas expresiones corresponden a una imagen de alumno, que separa los aspectos positivos de los negativos, no integrados al sujeto, sino que puestos afuera, en un contexto social y cultural riesgoso, peligroso e inseguro (11). Se interpela a los alumnos, de este modo, como sujetos a proteger, a cuidar, sujetos de la contención de la escuela. Las acciones del PEI tienen ese propósito, entre otras finalidades importantes: contener, cuidar, proteger, incluir.

EI PEI establece que la buena comunicación y vinculación es el valor principal asignado a las acciones de los proyectos que se llevan a cabo durante el año. La escuela valora que los profesores tengan un buen vínculo con sus alumnos, sin importar el campo disciplinar. Incluso, más allá del conocimiento que se enseña, lo valorado positivamente es la relación que establecen docentes y alumnos. En esta escuela, la ecuación se resuelve de la siguiente manera: las buenas vinculaciones ayudan y favorecen el aprendizaje. La asesora pedagógica lo expresa de la siguiente manera:

“... más allá de la materia, hay docentes que han generado un excelente vínculo, de comprensión, de tolerancia y que por parte del alumno han recibido mejor respuesta desde lo pedagógico que otros docentes que se vinculan de manera más rígidos, más direccional, más autoritaria..."

¿Cómo se construye un buen vínculo? Una profesora de lengua nos cuenta que sus alumnos no realizan tareas, no traen los materiales, que estudia poco. Son, en la expresión mundana escolar, unos vagos. En realidad, sus alumnos tienen bajo rendimiento escolar, pero son chicos disciplinados, comenta la profesora, con los que tiene una buena relación diaria. ¿Cómo caracteriza esa relación? Ella dice que tiene confianza en sus alumnos. No importa que tanto 
o tan poco sepan, lo importante es establecer, en su opinión, vinculaciones cercanas. Y para ella, la base del vínculo es la confianza, que se traduce como un comportamiento adecuado: los alumnos tienen "pautas" (normas de comportamiento), son chicos "sanos" (que no tienen malas intenciones)

Idéntica explicación da el equipo directivo. La clave para un buen vínculo es la confianza. "... la idea es que la relación vaya construyéndose sobre la confianza..." dice el Vicedirector. Todorov (2008) señala que el reconocimiento y la valoración del otro es una necesidad constitutiva de la subjetividad (12). Desde el nacimiento entramos a una red de relaciones sociales, por lo que aspirar al reconocimiento es una acción netamente humana, que produce, si es compartida, humanidad.

El director del CPEM cuenta que sus alumnos concurren al colegio con ganas, y que eso se debe a que encuentran un lugar al que asistir. Con una lógica feroz, entiende que "... estos edificios existen porque uno tiene alumnos." Así lo hace saber a los docentes, trazando el objetivo principal de su gestión: "Yo hice una reunión del personal y aclaré que el objetivo de las instituciones son los alumnos, y esa iba a ser mi mirada de la institución..." Esta primacía de los alumnos también puede interpretarse como la producción de un lugar físico y simbólico, en el que los alumnos concurren y se incluyen activamente. Es, para los docentes, un lugar de intercambio y aceptación. La asesora refiere que la escuela "... funciona como un lugar del que no se quieren ir...", probablemente porque provee de elementos culturales con las cuales identificarse; la permanencia en el lugar se asocia con la existencia de un imaginario que incluye a todos. Los proyectos del PEI se orientan según esa finalidad: los deportes intercursos, el campamento de bienvenida, la fiesta de fin de año, la asesoría a los padres y alumnos, etc. Todas son acciones, con cierto nivel de organización y permanencia, que tienen por finalidad la inclusión a un espacio significado desde la pertenencia a una cultura institucional que valora la relación docente - alumno.

\section{El valor de la palabra que enuncia}

Los alumnos de la escuela estudiada son demandados por efecto de la palabra. Es un discurso que los incluye como sujetos del lenguaje, de la expresión, en tanto recuperan la capacidad de decir y de hacer. El equipo directivo no se cansa de promover la palabra como forma de vinculación preponderante en la escuela. La palabra es el inicio y también el límite de lo que se puede o no hacer en la escuela. Dicen que "Si yo (el Vicedirector) tengo algo que decirle a fulana y tengo argumento para decir lo que digo, puedo decirlo y tengo que decir el argumento. Pero no insultos, porque no nos insultamos". La apelación al uso de la palabra como forma de vinculación es un imperativo, se establece como modo preferencial al que todos deben ajustar sus conductas. Es una regulación, una norma altamente significativa establecida para todos, no sólo 
para los alumnos, sino también para los docentes. La Asesora Pedagógica señala que a los profesores se les requiere debatir y discutir sobre los aspectos del trabajo docente, pero tal discusión tiene la finalidad de lograr consenso. Dice: “... consenso siempre a través del diálogo." Y lo repite insistentemente durante toda la entrevista. Creemos que este es uno de los lemas que orientan las acciones del PEI. Se debate, se discute, pero usando la palabra dentro de los límites establecidos para su uso.

Uno de los límites es el argumento. Se puede hablar, pero con argumentos. Se argumenta cuando hay razones, esto es: motivos y racionalidad. Así lo expresa el vicedirector: "... detrás de cada decisión que uno toma, sobre todo de aquellas en las cuales ellos resultan perjudicados, tienen una explicación." Esa explicación tiene que ser racional, porque de lo contrario, para el equipo directivo, se es irracional y no hay motivos para hacer ni decir. Observamos que en situaciones de conflicto entre alumnos, estos valores interactúan, proveyendo de un marco para la acción. Es decir, establecen cierto encuadre para la conducta, haciéndola previsible. El equipo directivo propone volver a la inocencia de la infancia (a un ideal de sujeto), como una manera de asumir una actitud positiva que contribuye a la resolución de los conflictos: ser como niños, nos comentan, y luego agregan que "...volver a confiar en la figura de alguien como para decir: bueno, yo puedo decir lo que pienso sin agredir y poder argumentar $y, \ldots$ se me va a dejar hablar y después veremos qué pasa."

A los alumnos no sólo se los incluye en el PEI desde el valor que tiene la palabra en la cultura institucional, sino también se los incluye desde la relación con los docentes - adultos que ocupan un lugar de responsabilidad y compromiso con el proyecto escolar. El Vicedirector recalca que “... uno no es otra cosa que un adulto con responsabilidad sobre ellos...". Esta es un rol que cumplen todos los docentes dentro de una organización educativa; su novedad es el valor como imagen - significado que introduce un orden en la relación con los alumnos. Pensamos que la responsabilidad y el compromiso por el proyecto, desde el lugar de docente - adulto, se ubica dentro de las representaciones construidas por la cultura escolar, con extensa tradición en la historia del CPEM. No abordaremos aquí esa tradición, que excede los límites del texto, en cambio subrayamos su articulación con otros significados, en especial los que se relaciona con el valor educativo asignado a "dar el ejemplo".

Los docentes de la escuela estudiada dan el ejemplo y deben sostener una actitud ejemplar, sobre todo cuando utilizan la palabra empeñada como modo de vinculación con los alumnos. El vicedirector destaca que “... ellos saben que yo puedo equivocarme pero saben que no les miento y que trabajo mucho. Cuando digo algo seriamente lo cumplo." La palabra enunciada tiene valor por sí, y de ese mismo modo es requerida también a los alumnos en situaciones de conflicto. El vicedirector nos cuenta que "... empezamos a trabajar la idea de la palabra. Hablamos, hablamos y hablamos,...”. En sintonía 
con esta idea, la Asesora Pedagógica nos relata que el diálogo y el consenso son dos herramientas con que utilizan ante las situaciones de violencia entre alumnos: “... se trata de establecer diálogos para no llegar a mayores...". La misma estrategia es empleada con los docentes, en la tarea de mediación en el aula. Nos dice que se trata de "... establecer este vínculo de escucha, de pertenencia, de contención, y trabajar en conjunto alumnos y docentes para modificar, cambiar la metodología, siempre a través del diálogo,..."

Es decir, la palabra es valorada por sí misma y como mediación entre pensamiento y acción. Pero además, es puesta en un lugar ejemplar, articulada a los valores de responsabilidad y compromiso. De todos los integrantes de la institución se espera que asuman estos valores, pero en especial a los docentes, ya que son los adultos en la relación con los alumnos. Creemos que no es sólo una cuestión de relación intergeneracional, sino que aparece la transmisión de un legado cultural, de una positividad que es constituyente del vínculo. Por esta razón, por su importancia en la construcción de intersubjetividad, pensamos que son valores que se establecen como normas reguladoras de las conductas en la institución.

Como dijimos, la ejemplaridad de la acción es puesta de un modo que produce relación, no es sólo una moral (un deber ser del maestro), sino también una ética ligada a la creación de los modos de vinculación docente - alumno. En las entrevistas encontramos insistentes menciones a "bancarse lo que viene" si se les da la palabra a los alumnos, y a ser ellos mismo "confiables", ya que la palabra dada o proferida en la relación tiene un valor importantísimo.

El ejemplo educa y es para todos. Así lo explica el Vicedirector: “¿Qué es ser vicedirector? Yo les digo a mis compañeros: yo soy un compañero de trabajo de ustedes que tiene responsabilidades distintas. Yo soy un compañero de trabajo. Lo que uno trata de hacer es dar el ejemplo."

Las imágenes - ideales que sostiene la escuela enhebran las acciones de los sujetos. En tiempos que habitar lo escolar resulta en una tarea desprovista de significados definidos de antemano, que garanticen el normal funcionamiento de la institución, el PEI resulta de un organizador de los valores y representaciones que permiten sostener proyecto y tarea.

\section{Una escuela que puede}

Las entrevistas realizadas a los integrantes del equipo directivo del CPEM estudiado, narran la vinculación de la escuela con el contexto, relación que expresa la emergencia de la adversidad. Tematizado como inseguro y riesgoso, el contexto se articula con elementos que provienen de la cultura escolar establecida, generando un espacio donde lo sentidos y significados otorgados a lo posible (y lo no - posible) operan enmarcando las conductas de las personas.

En las actuales condiciones sociales, lo posible no siempre alcanza. Asegurar los aprendizajes, promover identidades, incentivar el deseo por co- 
nocer, facilitar el pasaje a los estudios superiores y el trabajo, etc., todas son tareas de la escuela secundaria. Llevarlas a cabo requiere de un esfuerzo que más de las veces no se ve suficientemente recompensado, ni en términos de reconocimiento social ni en gratificaciones psíquicas; el desconcierto que ello provoca es precisamente el tránsito hacia el conocimiento de las instituciones (Kaës, 2002).

Aún así, la perplejidad en que se ven sumidas las instituciones escolares ante una situación que no acompaña como antes los procesos educativos, encontramos que el CPEM estudiado opera movilizando todos sus recursos materiales y simbólicos en pos del proyecto educativo que lo identifica frente a otras instituciones de la zona. La centralidad de los alumnos en el PEI, el valor otorgado a la palabra, el reconocimiento del otro a través de los valores de respeto, responsabilidad y confianza, la construcción de buenas vinculaciones entre docentes y alumnos, y otros elementos no descriptos aquí, dan cuenta de lo ocupada que está la escuela en dinamizar la relación con el contexto a través de los procesos productivos de su cultura institucional.

Observamos que esta dinámica favorece la construcción de intersubjetividades pedagógicas, entendiendo que ésta es posible a partir de las interacciones entre docentes - alumnos y la definición compartida de la situación, tal como expresamos anteriormente. Sugerimos, en nuestra investigación, que la visibilidad de los alumnos en tanto sujetos que desean, y de los docentes como adultos responsables, crean los elementos principales para la creación de condiciones de educabilidad favorables. Estos elementos se registran en lo institucional e interactúan con ella. Están ahí, interjuegan con el contexto, son una positividad que se efectúa por la actividad de los sujetos. Están disponibles a nivel institucional, en la cultura y el estilo particular que tiene el CPEM estudiado. Y si bien son significados y sentidos que operan en ese registro, vemos que el equipo directivo los concretiza en las acciones diseñadas para el PEI. El hecho que no esté escrito no desmejora ni disminuye las posibilidades que brinda como organizador de la tarea y el proyecto escolar.

En nuestra opinión, una escuela puede con aquello que tiene entre sus bagajes culturales, pero también por la actividad decidida de sus integrantes de ponerlos en funcionamiento. Es probable que las investigaciones en torno a la educabilidad y a la construcción social del riesgo educativo requiera repensar los elementos reseñados: la cultura institucional y la producción de intersubjetividad pedagógica. Son conceptos que deberían tenerse especialmente en cuenta en los debates sobre escuela y fracaso escolar. 


\section{Notas Bibliográficas}

(1) Según las estadísticas provistas por la Dirección Provincial de Estadísticas y Censo, para el año 2010, vivían en el departamento confluencia (cuya cabecera es la Ciudad de Neuquén) 362.673 personas, de los cuales el $12 \%$ son desocupados y el 9,3\% se encuentra bajo la línea de pobreza. El $13 \%$ de los hogares figuran dentro de los porcentuales NBI, 55 de cada 100 trabajadores en actividad no han logrado completar sus estudios secundarios y sólo 18 de los restantes trabajadores poseen títulos universitarios. Cerca de 2000 jóvenes tienen entre 15 y 17 años, constituyendo la población potencial de la escuela secundaria de la zona. Un 2,3 \% de la población mayor de 14 años es analfabeta.

(2) De aquí en adelante, las citas de entrevistas se refieren a las realizadas al equipo directivo de la escuela estudiada, durante el año 2011, en el marco del proyecto de investigación $N^{\circ}$ 085/10 Facultad de Ciencias de la Educación - Universidad Nacional del Comahue.

(3) Comprendemos al equipo directivo conformado por el Director, los Vicedirectores de ambos turnos y la Asesora Pedagógica.

(4) Lo "común" en la cultura institucional es tema de estudio y debate. A los fines del artículo, comprendemos eso común a partir del reconocimiento compartido entre los sujetos de la institución, que crea un sentido y un sentimiento de pertenencia, de pertenecer "a algo" y por ello, de deberse a esa inclusión. Espósito (2007) señala que lo comunitario no es más que la sustracción, lo impropio, el común deber que genera pertenencia. Nosotros encontramos que en la base comunitaria (en su munus) se desarrolla también una potente adhesión al proyecto y la tarea de la escuela. Esta particularidad se observa en la sustanciación del Proyecto Educativo Institucional. Con esto indicamos que lo comunitario no es sólo una expresión de cesión, sino también una opción de los docentes por la escuela. ¿Cuál es esa tarea y ese proyecto al que adhieren, no sólo docentes, sino también los alumnos? Anticipamos una de nuestras conclusiones; Agamben (1996) nos recuerda que importan los sujetos en sí; el ser, sea cual sea. Nos plegamos a esa expresión, a la vez que observamos su pertinencia al estudio de investigación: importan los alumnos, cualquiera de ellos, parecieran decir, sin dobleces, los docentes del CPEM estudiado.

(5) Kaës advierte que la dificultad en el conocimiento de las instituciones deviene de su carácter bifronte. Citamos: "... la institución nos precede, nos sitúa y nos inscribe en sus vínculos y sus discursos; pero con este pensamiento que socava la ilusión centrista de nuestro narcisismo secundario, descubriendo también que la institución nos estructura y que trabamos con ella relaciones que sostienen nuestra identidad." La cita es más extensa y alude a que las instituciones habitan en el registro de lo inconsciente colectivo, por lo que deben ser consideradas el trasfondo de la vida psíquica individual. Párrafos más adelante afirma lo siguiente: "(la institución) Es constituyente de los espacios psíquicos comunes que son coextensivos a los agrupamientos de diversos tipos. El correlato interno de este externalizado común indiferenciado es probablemente uno de los componentes del inconsciente" (Kaës, 2002, 16 - 17).

(6) Acerca del concepto de organizador, Fernández lo conceptualiza de la siguiente manera: "Largamente utilizado en las ciencias humanas, el concepto de organizador nos sirve para explicar esa regulación (del individuo y la tarea). Se entiende por tal el aspecto, el acto o el hecho que provocan la ordenación de las relaciones y las acciones dentro de un marco o pauta que les da sentido" (Fernández, 2001, 99).

(7) Desde las perspectivas situacionales, contextualistas e interaccionistas del aprendizaje, como la que sostenemos en el artículo, entendemos el riesgo educativo no en términos de una propiedad subjetiva, sino de las interacciones de los sujetos en la situación 
pedagógica y estas en las prácticas culturales del sistema escolar. De aquí su carácter de construcción social. Por esto mismo, las condiciones de educabilidad se refieren a la posibilidad que tienen las escuelas de crear las mejores condiciones pedagógicas para que el aprendizaje sea una realidad, diferenciándonos de esta manera con los modelos patológicos tradicionales del aprendizaje que ponen en el centro del fracaso escolar a los sujetos individuales.

(8) Redefinir la relación entre riesgo educativo y condiciones de educabilidad nos ha permitido relocalizar la mirada sobre el fracaso escolar, haciendo foco en el fenómeno de la intersubjetividad y la cultura escolar. De ahí la pertinencia del concepto educabilidad para nuestro proyecto de investigación, tal como es tomado por R. Baquero. Un poco más allá de esta idea, F. Terigi (2009) señala que la reconceptualización situacional permite pensar la educabilidad como un problema político - educativo acerca de las condiciones escolares que deben ser promovidas y removidas para alcanzar la efectiva inclusión de los sujetos a la experiencia escolar. Entendemos que la intersubjetividad y cultura escolar se formula dentro de esas condiciones.

(9) Vale la siguiente aclaración: no tomamos al equipo directivo como un bloque cerrado, sin discordancias ni conflictos. Los juegos de intereses y deseos y las singularidades de los actores confluyen en el entramado institucional, construyendo la organización concreta, con sus particulares conflictos y problemas. Pero a los fines del análisis, como dijimos al comienzo del artículo, presentamos aquellas regularidades en los discursos y acciones de los integrantes del equipo directivo que trazan una identidad o, más bien, una característica propia y que se sostiene en sendos significados culturales.

(10) El acontecimiento produce una novedad. Para los docentes entrevistados, las situaciones se revelan no por las demandas de una respuesta universal (un problema, una solución conocida y escolarizada), sino por la producción de lo nuevo. Entendemos que lo novedoso se instala desde la multiplicidad de hechos; en realidad, por la multiplicidad de afectaciones que las situaciones y las respuestas pueden generar. Estas articulaciones parecen realizarse siguiendo trayectos rizomáticos, como aparentemente surgen de las entrevistas realizadas, aunque también encontramos que reconocen una linealidad y continuidad, más propia del tipo radicante. Sobre estos conceptos, ver Lazzarato, M. (2006) Deleuze G. y Guattari, f. (1991) Borriaud, N. (2009).

(11) Nos sentimos tentados a proponer que el grupo docente opera clivando los aspectos negativos de los sujetos, depositándolos en el exterior de la escuela, de manera de poder funcionar satisfactoriamente a pesar de un contexto que le es adverso. Este clivaje mantiene a raya lo sincrético, lo indiscriminado que remite a una escena inicial y originaria, donde no hay discriminación entre el yo y el no - yo, o entre la sociabilidad y la no - sociabilidad. José Bleger, en sus numerosos textos, indica que esa separación (sociabilidad sincrética) es necesaria para el buen funcionamiento de los grupos. Su ausencia produce serios trastornos en la personalidad. Vale la aclaración: la evidencia recolectada puede anudar explicaciones de orden psicosocial, pero nuestra intención no es incorporar este tipo de análisis. Simplemente, sabemos de sus posibilidades para la comprensión de la realidad institucional, pero nos dirigimos más bien a tratar de entender qué sucede en la escuela estudiada, en relación a los vínculos de orden intersubjetivos, a favor de comprenderla pedagógicamente y no psicosocialmente.

(12) Todorov reconoce la existencia biológica, incluso, a un nivel cósmico, la existencia compuesta de minerales. Una línea separa la vida mineral y animal de la existencia social y humana. Esa separación es una frontera que marca "positivamente" (constitutivamente) a los sujetos: de un lado, la inmovilidad de lo concreto, la repetición mecánica, y también la vida en un cuerpo, las necesidades del animal. Del otro, la existencia humana. Ver en Tzvetan Todorov (2008). La idea de una existencia que tiene su origen en el reconoci- 
miento del otro, tal como ese otro se presenta, permite pensar una ética, cuyo cometido no supone un destino o una tarea definida, sino una realización de sí tal como este sí se desarrolla. Al respecto, Agamben (1990; 2006). Esta idea de un sujeto tal como es, en sí mismo, que se afirma por el otro, nos posibilita superar las representaciones del alumno como una extensión de la propiedad sujeto - alumno. Como en una serigrafía, cada elemento compone un original y no una repetición. Esto se advierte en el esfuerzo de los docentes del equipo directivo de reconocer en particular a cada alumno y docente, acción que origina un proceso subjetivante.

\section{Referencias Bibliográficas}

- $\quad$ Agamben, G. (1996) La comunidad que viene. Valencia: Pre - Textos.

- Baquero, R. (2002) La educabilidad bajo sospecha. Cuadernos de Pedagogía Rosario, Año I, Vol. 9; $71-85$,

- Espósito, R. (2007) Communitas. Origen y destino de la comunidad. Buenos Aires: Amorrortu.

- $\quad$ Fernández, L. (1998) El análisis de lo institucional en la escuela. Un aporte a la formación autogestionaria para el uso de los enfoques institucionales. Buenos Aires: Paidós.

- $\quad$ Frigerio, G. y Poggi, M. (1992). Intersticios, transposición y textos. Buenos Aires: Miño y Dávila.

- Garay, L. (1996). La cuestión Institucional de la educación y las escuelas: conceptos y reflexiones. En Butelman, I. (Comp.) Pensando las instituciones, sobre críticas y prácticas en educación. Buenos Aires: Paidós.

- Goetz, J. P. y LeCompte, M. D. (1988) Etnografía y diseño cualitativo en investigación educativa. Evaluación del diseño etnográfico. Madrid: Ediciones Morata.

- Greco, María B. (2007) La autoridad (pedagógica) en cuestión. Una crítica al concepto de autoridad en tiempos de transformación. Rosario: Homo Sapiens.

- Kaës, R. (1989) Realidad psíquica y sufrimiento en las instituciones. En Kaës, R.; Bleger, J.; Enriquez, E.; Fornari, F.; Fustier, P.; Roussillon, R. y Vidal, J.P. La institución y las instituciones. Estudios psicoanalíticos. (pp. 15 - 67) Buenos Aires: Paidós.

- Lazzarato, M. (2006) Políticas del acontecimiento. Buenos Aires: Tinta Limón.

- Terigi, F. (2009). El fracaso escolar desde la perspectiva psicoeducativa: hacia una reconceptualización situacional. Revista Ibeoramericana de Educación (50), 23 - 29.

- Todorov, T. (2008) La vida en común. Ensayo de antropología general. Buenos Aires: Taurus.

- Vigotsky, L. (1995) Historia del desarrollo de las funciones psíquicas superiores. Obras Escogidas (Tomo III). Madrid: Visor.

- Wertch, J. (1988) Vygotski y la formación social de la mente. Barcelona: Paidós.

- Yentel, N. (Coord.) (2009) Directores y escuelas. Una experiencia de formación. Neuquén: EDUCO. 